\title{
Otolaryngologists: How Safe They are from Skin Infections?
}

\author{
${ }^{1}$ Jyotika Kalsy, ${ }^{2}$ PS Kalra, ${ }^{3}$ KJPS Puri \\ ${ }^{1}$ Senior Resident, Department of Dermatology, Venereology and Leprosy, Government Medical College, Amritsar, Punjab, India \\ ${ }^{2}$ Associate Professor, Department of ENT, Sri Guru Ram Das Institute of Medical Sciences, Amritsar, Punjab, India \\ ${ }^{3}$ Professor and Head, Department of Dermatology, Venereology and Leprosy, Government Medical College, Amritsar, Punjab, India
}

Correspondence: Jyotika Kalsy, Senior Resident, Department of Dermatology, Venereology and Leprosy, 129 A Race Course Road, Opposite Beams Hospital, Amritsar, Punjab-143001, India, Phone: 09814134141, e-mail: jyotideepan@yahoo.co.in

\section{ABSTRACT}

Otolaryngologists are daily examining patients both in clinics and theaters which makes them vulnerable to acquire infections. Aim: To highlight the early signs and symptoms of skin infections in patients coming to otolaryngology department and to learn to safeguard oneself from contagious skin problems as many of them are contagious in their early stages of evolution.

Patients and methods: Over a period of 1 year, 2,450 patients were screened for the skin problems. The patients were examined clinically by dermatologist for contagious skin diseases. Photographs were taken and necessary investigations done, like scrapings for fungus in $10 \%$ $\mathrm{KOH}$ under direct microscopy, pus for culture sensitivity for fungus, bacteria and virus, tzanck smear, direct examination of expressed material under microscope skin biopsy.

Results: Out of the 2,450 patients, $182(7.4 \%)$ patients were found to have skin diseases with high and low virulence. They were in the age range from 1 to 66 years. Around $111(60.99 \%)$ patients were females and $71(39.01 \%)$ males. It was found that maximum patients were in the age group of 20 to 40 years. Majority of the diseases were bacterial in nature in 72 (39.5\%) patients, followed by superficial fungal infections in 56 (30.9\%) patients, viral infections in $36(19.7 \%)$ and arthropod infections in $18(9.9 \%)$ patients.

Conclusion: Otolaryngologists are daily examining patients both in clinics and theaters which makes them more prone to acquire infections. So, the emphasis of study is to be able to diagnose, treat and safeguard oneself from these skin infections.

Keywords: Skin, Head and neck infections.

\section{INTRODUCTION}

Otolaryngologists are vulnerable to skin infections in their daily routine of examining patients in clinics and theaters.

The most important protective factor in prevention of these infections is an intact stratum corneum, the tough barrier of protein and lipid formed on the cutaneous surface by the underlying epidermis. ${ }^{1}$

Cutaneous infections occur when the skin's protective mechanisms fail, especially when trauma, inflammation, maceration from excessive moisture or other factors disrupt the stratum corneum. The organisms causing infection may originate from patient's own resident flora, either on the skin or the adjacent mucous membranes, but may come from other people, animals or the environment. ${ }^{2}$

\section{PATIENTS AND METHODS}

Over the time period of 1 year, 2,450 patients were examined in otolaryngology outpatient department and patients were referred to dermatology department for expert opinion regarding any associated skin diseases. Photographs were taken and necessary investigations were done wherever needed, like scrapings for fungus in $10 \% \mathrm{KOH}$ under direct microscopy, pus for culture sensitivity for fungus, bacteria and virus, tzanck smear, direct examination of expressed material under microscope and skin biopsy.

\section{RESULTS}

Out of the 2,450 patients examined, 182 (7.4\%) patients were found to have skin diseases with high and low virulence. They were in the age range from 1 to 66 years. There were 111 (60.99\%) females and 71 (39.01\%) males. It was found that maximum patients were in the age group of 20 to 40 years (Graph 1). Majority of the diseases were bacterial in nature in 72 (39.5\%) patients, followed by superficial fungal infections in 56 (30.9\%) patients, viral infections in 36 (19.7\%) and arthropod infections in 18 (9.9\%) patients (Table 1).

\section{DISCUSSION}

Screening of 2,450 patients over a period of 1 year shows that $182(7.4 \%)$ patients were found to have contagious skin infections. The examining physician is at risk, if he/she is not aware about the contagious nature of the diseases. 


\begin{tabular}{|c|c|c|c|c|}
\hline S. no & Skin infections & & No. of patients & Percentage \\
\hline \multirow[t]{5}{*}{1.} & \multirow[t]{5}{*}{ Bacterial } & Folliculitis & 45 & 62.5 \\
\hline & & Furuncle & 14 & 19.44 \\
\hline & & Impetigo & 6 & 8.33 \\
\hline & & Carbuncle & 5 & 6.94 \\
\hline & & Leprosy & 2 & 2.77 \\
\hline \multirow[t]{2}{*}{2.} & \multirow[t]{2}{*}{ Superficial fungal } & Tinea & 41 & 73.21 \\
\hline & & Candida & 15 & 26.79 \\
\hline \multirow[t]{5}{*}{3.} & \multirow[t]{5}{*}{ Viral } & Molluscum contagiosum & 17 & 47.2 \\
\hline & & Warts & 11 & 30.5 \\
\hline & & Chickenpox & 5 & 13.9 \\
\hline & & Herpes simplex & 2 & 5.6 \\
\hline & & Herpes zoster & 1 & 2.8 \\
\hline 4. & Arthropod & Scabies & 18 & 9.9 \\
\hline
\end{tabular}

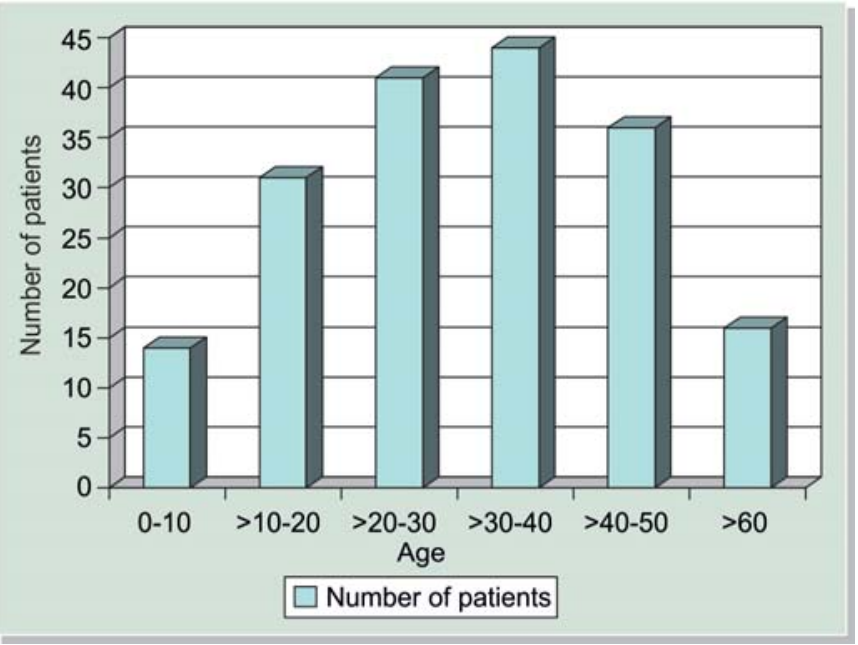

Graph 1: Age distribution of patients included in the study

Maximum diseases belonged to bacterial group 72 (39.5\%). Mostly these are due to Staphylococci aureus which is a gram-positive bacteria commonly found as a part of human flora in the axilla, the inguinal, perineal areas and anterior nares. ${ }^{3}$ Pure Staphylococcus lesions are pustules, bullae and yellow brown or honey colored crusted lesions which can infect if the skin surfaces are breached. Bacteria can survive for hours to weeks or even months on dry environmental surfaces depending on the strain. ${ }^{4}$ So one has to be very careful while examining the patients with boils or pustules. Two cases (2.77\%) of Hansen's disease were detected. They reported first in the ENT OPD with the complaint of epistaxis. After ruling out the other causes of epistaxis, they were sent for dermatological opinion. In one case, there were multiple erythematous plaques over face and body with thickened nerves, skin biopsy was positive for acidfast bacilli, diagnosis of lepromatous leprosy was made (Fig. 1). In the second case, there was only glove and stocking anesthesia with thickened nerves. Other neural causes were ruled out after taking opinion from the neurologist, as there was no skin lesion diagnosis of neural leprosy was made.

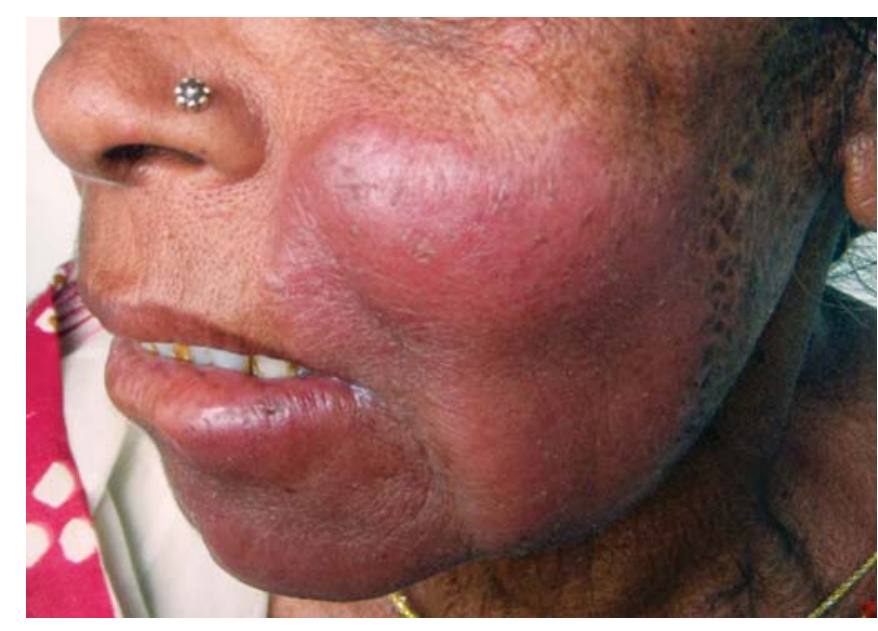

Fig. 1: The plaque on face (leprosy)

Hansen's disease or leprosy is a granulomatous disease of peripheral nerves, mucosa of upper respiratory tract and skin lesions are primarily external sign. Davey and Rees indicated that nasal secretions from lepromatous patients could yield as much as 10 million viable organism per day. ${ }^{5}$ The clinical manifestations are varied but mainly hypoesthetic, hypopigmented or erythematous macule or just area of sensory loss, spontaneous blisters on hands and feet, nasal stuffiness, epistaxis, painless nodules on any part of body.

These cases presented first to the otolaryngologist so in every case of epistaxis leprosy should be kept in the differential.

Superficial fungal infections were seen in 56 (30.9\%) cases. The mode of spread of these infections is by contact with an infected person or animal. Fomites, such as infected combs, brushes, caps, hats, couches, floors of swimming baths, also transmit infection. ${ }^{6}$ Warmth and humidity favor the occurrence of this infection, therefore, tropical and subtropical regions have a higher incidence of disease. ${ }^{7}$ Clinically, tinea (dermatophyte infection) is seen as annular lesion with active erythematous and spreading borders with 
central clearing (Fig. 2). Candida infection on skin is seen as moist, erythematous rash with satellite lesions. During the summer season, these infections are very common in the OPD and, if there is any break in the skin or the immune system is compromised, one can catch these infections easily.

Thirty-six (19.7\%) cases belonged to viral group of infections. Molluscum contagiosum is universally occurring infection commonly affecting children, sexually-active adults and immunocompromised individuals. Infection occurs either by direct skin to skin contact or indirectly by means of fomites. ${ }^{8}$ Typical lesion is discrete dome-shaped umblicated waxy papules. In HIV-infected patients, skin lesions are numerous, larger, persist longer and are commonly seen on face (Fig. 3). Warts are benign proliferation of the skin resulting from infection with human papilloma virus and can occur at any age. Transmission occurs by means of physical contact with a contaminated object, e.g. the wart itself or toys, and the impairment of epithelial barrier function from trauma, maceration or both can predispose to infection. They appear as verrucous papules varying from $1 \mathrm{~mm}$ to $1 \mathrm{~cm}$ in diameter. ${ }^{9}$ Warts and

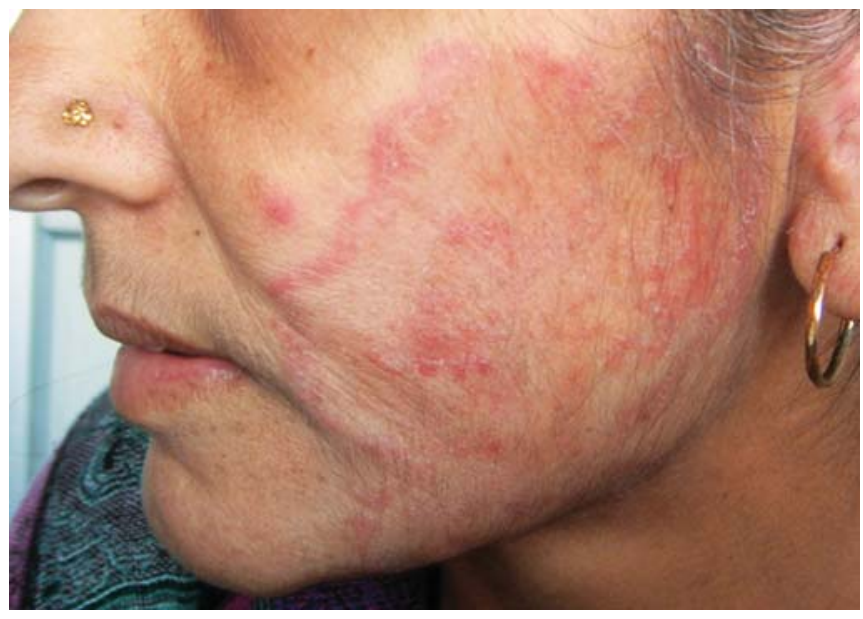

Fig. 2: The scaly plaque of tinea

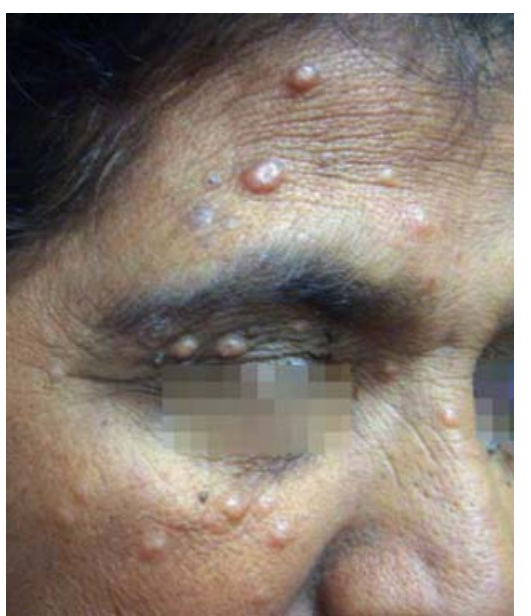

Fig. 3: Papules of molluscum contagiosum molluscum contagiosum were incidental findings in our patients but important for the examining practitioner.

Chickenpox (varicella) is highly contagious febrile illness characterized by generalized pruritic vesicular rash and is most prevalent in childhood. Patient is infectious for 1 to 2 days before exanthema and 4 to 5 days after exanthema or till the last vesicle has crusted. It is through respiratory droplets or by contact with the infectious vesicular fluid. ${ }^{10}$ High index of suspicion was required in these cases as if left undiagnosed could be a risk to the medical professionals and also to the other patients in the OPD (Figs 4 and 5).

Herpes simplex or cold sore is commonly occurring ailment. Disease starts as febrile illness with small grouped vesicles or shallow ulcers in oral mucosa, periorally and may extend some distance away from mouth. Approximately, one-third infected individuals suffer relapses. Humans remain the sole reservoir for transmission of these viruses to other humans 60 to $90 \%$ of the people worldwide are seropositive. It spreads by direct contact or with droplets from the infected secretions. Transmission is generally during the periods of asymptomatic shedding. Virus is

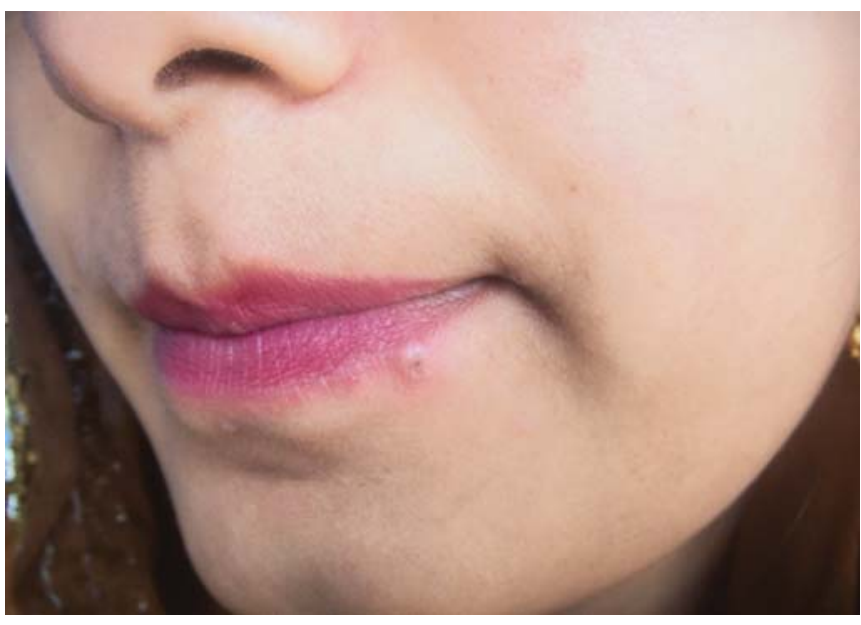

Fig. 4: Single vesicle on lip (chickenpox)

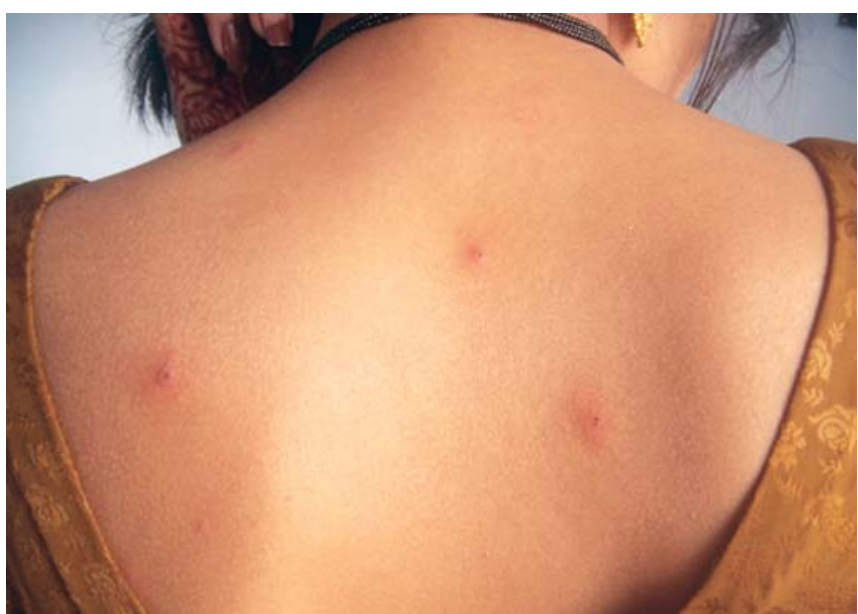

Fig. 5: Papules and vesicles on back of the same patient as in Figure 4 
transmitted during the close personal contact through exchange of saliva, semen, cervical fluid or vesicle fluid from active lesions. The virus must come in contact with mucosal surfaces or abraded skin, where it replicates first and initiates infection. ${ }^{11}$ One case in our study was of herpetic gingivostomatitis with fever and sore throat and the other one was having grouped vesicles on the lips (Fig. 6). Both these cases were having potential of transmitting the infection, if examined without gloves.

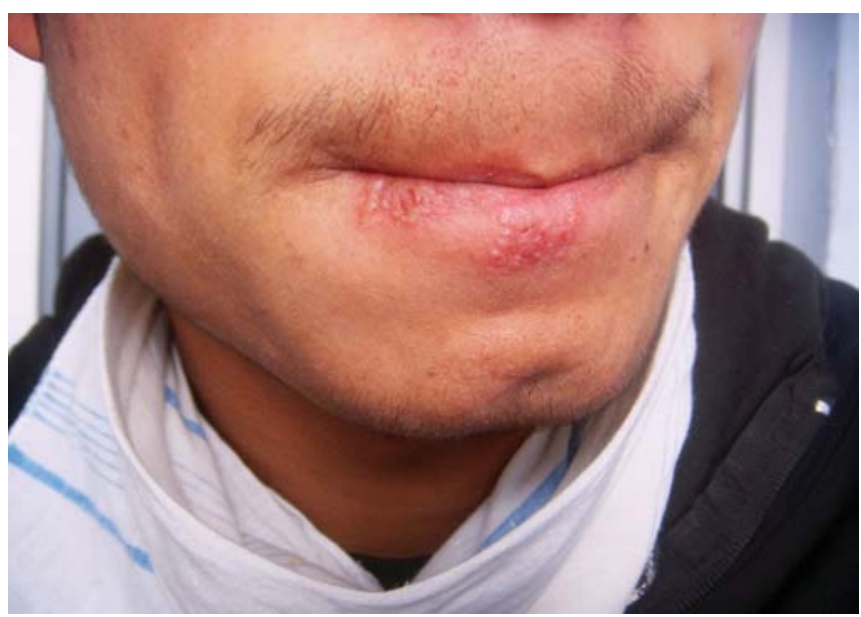

Fig. 6: Grouped vesicles on the vermilion border of lower lip (Herpes simplex)

Herpes zoster is a localized disease characterized by unilateral radicular pain with grouped red papules which rapidly becomes vesicular and pustular limited to a dermatome. It is caused by reactivation of varicella zoster virus lying dormant in the sensory ganglion. ${ }^{12}$ Most adults are at risk of varicella zoster reactivation. Full blown cases can easily be diagnosed by an ENT surgeon but high index of suspicion is required in the early stages of evolution of disease.

Around 18 (9.9\%) cases of scabies were diagnosed. Scabies belongs to arthropod group of infections. Sarcoptes scabiei var hominis causes highly pruritic and contagious skin infestation affecting all races and social classes. Skin lesions are erythematous, excoriated papules or papulovesicles which get secondarily infected. It was shown that close contact for 15 to 20 minutes with infected person is adequate for transmission of the disease. ${ }^{13}$ A person infested with mites can spread scabies even if he or she is asymptomatic. In infantile scabies, vesicular lesions are seen on head, neck, palms and soles ${ }^{6}$ (Figs 7 and 8). Since majority of our cases of scabies were infants and it can definitely infect the examining physician, if one is not keeping scabies in the mind.

On review of the literature, no sufficient data is available regarding the prevalence of skin infections in otolaryngology OPD. These infections can be a potential risk to the

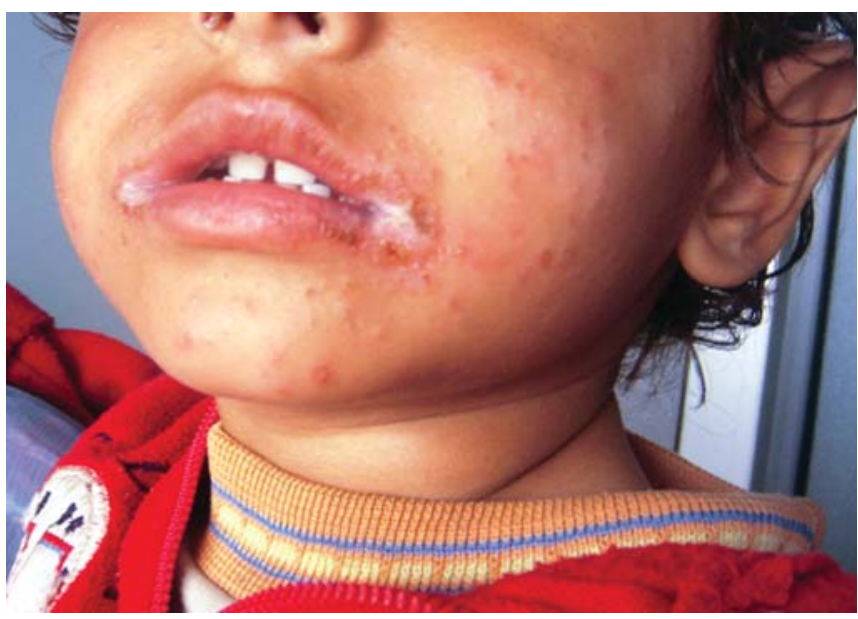

Fig. 7: Eczematous skin lesions on face (scabies)

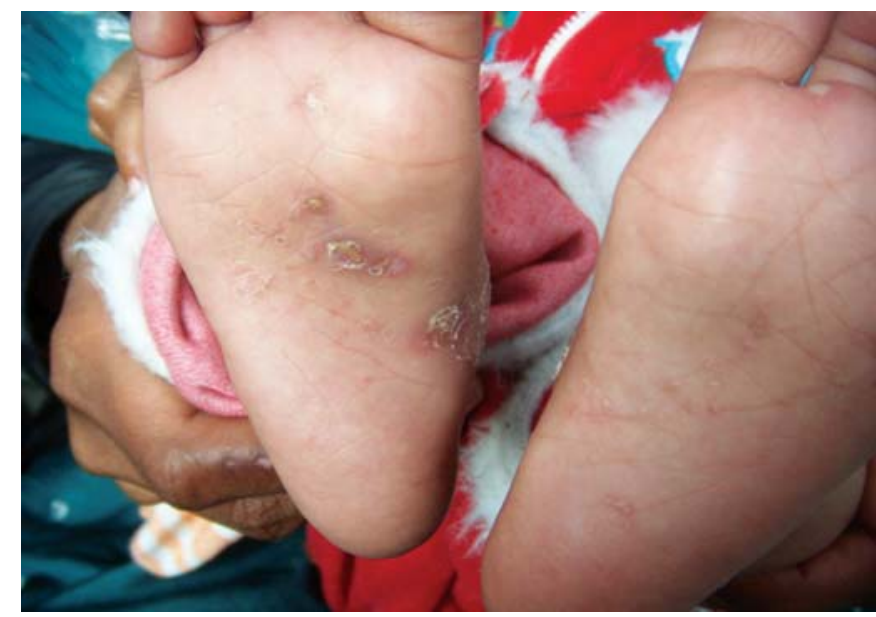

Fig. 8: Papules and pustules on soles in the same patient as in Figure 7

examining medical professional in its early stages of evolution and is important to limit the disease in the patient to decrease the risk of transmission. So, it is suggested that the following precautions should be taken while examining the patients:

- First and the foremost important is the thorough knowledge about these diseases

- First line of defence against germs is frequent and thorough washing of hands and skin surfaces

- Alcohol-based hand sanitizers are good alternates to soaps wherever necessary

- Gloves should be worn before touching mucous membrane, nonintact skin or any oozing surface

- Gloves should be changed after examining each patient

- Regular wearing of masks should be made a habit while examining the patients.

\section{REFERENCES}

1. Roth RR, James WD. Microbiology of skin: Resident flora, ecology, infection. J am Acad Dermatol 1989;20:367. 
2. Hirschmann JV. Fungal, bacterial and viral infections of the skin. Derm 2010;VII:1

3. Von Eiff C, Becker K, et al. Nasal carriage as a source of Staphylococcus aureus bacteremia. Study Group. N Engl J Med 2001;344(1):11-16.

4. Cimolai. MRSA and the environment: Implications for comprehensive control measures. European Journal of Clinical Microbiology \& Infectious Diseases: Official Publication of the European Society of Clinical Microbiology 2008;27(7): 481-93.

5. Davey T, Rees R. The nasal discharge in leprosy: Clinical and bacteriological aspects. Lepr Rev 1974;45(2):121-34.

6. Sarkar R, Kanwar AJ. Three common dermatological disorders in children (scabies, pediculosis and dermatophytoses). Indian Pediatrics 2001;38:995-1008.
7. Martin AG, Kobayashi GS. Fungal diseases with cutaneous involvement. In: Fitzpatrick TB (Ed). Dermatology in General Medicine. McGraw-Hill, New York 1993;2:2421-51.

8. Esposito JJ, Fenner F. Poxvirus. In: Knipe DM, Howley PM, (Eds). Fields virology (4th ed). Philadelphia: Lippincott Williams Wilkins 2001:2886-2921.

9. Brentyans MH, Yung-Yue KA, Lee PC, Tyring SK. Human papilloma virus: A review. Dermatol Clin 2002;20:315-19.

10. Criton S. Viral infections: IADVL Textbook of Dermatology (3rd ed). Bhalani Publishing House, Mumbai, India 2008;14:344

11. Corey L. Infections with herpes simplex viruses. N Engl J Med 1980;314:686-91.

12. Burns T, Breathnach S, Cox N, Griffiths C. Virus infections: Rook's Textbook of Dermatology (7th ed). Oxford: Blackwell Publishing, USA 2004:25.1-25.83.

13. Lane AT. Scabies and head lice. Pediatric Ann 1987;16:51-54. 